\title{
Metabotropic Glutamate Receptor Subtype 8 in the Amygdala Modulates Thermal Threshold, Neurotransmitter Release, and Rostral Ventromedial Medulla Cell Activity in Inflammatory Pain
}

\author{
Enza Palazzo, ${ }^{1}$ Ida Marabese, ${ }^{1}$ Marie Soukupova, ${ }^{1,2}$ Livio Luongo, ${ }^{1}$ Serena Boccella, ${ }^{1}$ Catia Giordano, ${ }^{1}$ Vito de Novellis, \\ Francesca Rossi, ${ }^{1}$ and Sabatino Maione ${ }^{1}$ \\ ${ }^{1}$ Department of Experimental Medicine, Section of Pharmacology “L. Donatelli," Faculty of Medicine and Surgery, The Second University of Naples, 80138 \\ Naples, Italy, and 2Department of Pharmacology, Third Faculty of Medicine, Charles University of Prague, 10034 Prague, Czech Republic
}

The amygdala is a crucial area in controlling the threshold of pain and its emotional component. The present study has evaluated the effect of a metabotropic glutamate 8 receptor (mGluR8) stimulation in the central nucleus of the amygdala (CeA) on the thermoceptive threshold and on CeA serotonin (5-HT), glutamate (Glu), and GABA release in normal and carrageenan-induced inflammatory pain conditions in rats. Furthermore, the activity of rostral ventromedial medulla (RVM) putative "pronociceptive" $\mathrm{N}$ and "antinociceptive" OFF cells has been evaluated. (S)-3,4-Dicarboxyphenylglycine [(S)-3,4-DCPG], a selective mGluR8 agonist, administered into the CeA, did not change 5-HT, Glu, and GABA release, or the thermoceptive threshold, nor did it modify the activity of ON and OFF cells of the RVM in normal animals. In rats treated with carrageenan, intra-CeA (S)-3,4-DCPG perfusion produced antinociception, and increased 5-HT and Glu, whereas it decreased GABA release. Intra-CeA (S)-3,4-DCPG inhibited ON and increased OFF cell activities. Furthermore, an increase in $m$ GluR8 gene, protein, and staining, the latter being associated with vesicular GABA transporter-positive profiles, has been found in the $\mathrm{CeA}$ after carrageenan-induced inflammatory pain. These results show that stimulation of mGluR8, which was overexpressed within the $\mathrm{CeA}$ in inflammatory pain conditions, inhibits nociceptive behavior. Such an effect is associated with an increase in 5-HT and Glu release, a decrease in GABA, and the inhibition of ON- and the stimulation of OFF-cell activities within RVM.

\section{Introduction}

The amygdala is an important site in which the reciprocal interaction between chronic pain and negative affective states takes place (Heinricher and McGaraughty, 1999; Fields, 2000; Meagher et al., 2001). The laterocapsular division of the central nucleus of the amygdala $(\mathrm{CeA})$ has been defined as the "nociceptive amygdala" because of the high content of nociceptive neurons (Bourgeais et al., 2001; Neugebauer and Li, 2002, 2003; Li and Neugebauer, 2004). It receives ascending nociceptive signals (Bernard et al., 1996) and has efferent projections to areas that are involved in pain modulation (Rizvi et al., 1991; Van Bockstaele et al., 1996) such as direct and indirect projections to rostral ventromedial medulla (RVM) (Rizvi et al., 1991; Hermann et al., 1997; Gebhart, 2004). The role of the amygdala in the regulation of pain is dual, varying from pronociception (Manning, 1998; GreenwoodVan Meerveld et al., 2001) to antinociception (Helmstetter, 1992;

\footnotetext{
Received June 9, 2010; revised Nov. 18, 2010; accepted Dec. 6, 2010.

Financial support from MIUR-Italy (Ministero dell'Istruzione, dell'Università e della Ricerca) (Progetto di Ricerca di Rilevante Interesse Nazionale 2007, recipient S.M.) is gratefully acknowledged.

Correspondence should be addressed to either Enza Palazzo or Sabatino Maione, Department of Experimental Medicine, Section of Pharmacology "L. Donatelli", Faculty of Medicine and Surgery, II University of Naples, via Costantinopoli 16,80138 Naples, Italy, E-mail: enza.palazzo@unina2.it or sabatino.maione@unina2.it.

DOI:10.1523/JNEUROSCI.2938-10.2011

Copyright $\odot 2011$ the authors $\quad 0270-6474 / 11 / 314687-11 \$ 15.00 / 0$
}

Helmstetter and Bellgowan, 1993; Manning and Mayer, 1995; Mena et al., 1995; McGaraughty and Heinricher, 2002; Nandigama and Borszcz, 2003). Moreover, chronic pain conditions such as arthritic and neuropathic pain proved to be associated to central sensitization and synaptic plasticity in the CeA (Neugebauer and Li, 2003; Han et al., 2005; Ikeda et al., 2007; Ji and Neugebauer, 2007).

There is a large body of evidence suggesting that metabotropic glutamate receptors (mGluR1-8) control pain and pain-related affective responses within the amygdala (Neugebauer, 2007). A role in facilitating nociception and sensitization of group I mGluR1/5 has been demonstrated at multiple levels of the nociceptive circuit including the CeA (Neugebauer et al., 2003; Li and Neugebauer, 2004; Han and Neugebauer, 2005). At this level, stimulation of metabotropic glutamate 8 receptor (mGluR8) by $(S)$-3,4-dicarboxyphenylglycine $[(S)$-3,4-DCPG], a selective mGluR8 agonist (Schmid and Fendt, 2006), has instead been shown to have antinociceptive and anxiolytic properties in the arthritis pain model (Palazzo et al., 2008). As well as in the CeA, an antinociceptive effect due to mGluR8 stimulation by (S)-3,4DCPG has also been found within the periaqueductal gray (PAG) in inflammatory and neuropathic pain models (Marabese et al., 2007a). It has been shown that (S)-3,4-DCPG increases glutamate and decreases GABA release (Marabese et al., 2005) consis- 
tently with PAG-antinociceptive descending system activation and consequent antinociception. Apart from GABA and glutamate, serotonin (5-hydroxytryptamine, 5-HT) also plays a role in controlling behavioral responses to unpleasant stimuli such as pain at CeA level (Mo et al., 2008). Reciprocal interactions between serotonin, glutamate, and GABA, which have been reported in the limbic system and pain matrix areas (Maione et al., 1998; Ciranna, 2006), have relevant meaning in both pain and pain-related anxiety as well as depression establishment and maintenance (Curzon, 1988; Wang and Nakai, 1994; Kalia, 2005; Phelps and LeDoux, 2005). The biochemical and functional changes associated with the antinociceptive and anxiolytic actions of (S)-3,4-DCPG in the CeA are still unknown. Based on CeA plasticity occurring after prolonged pain stimuli and the mGluR8 capability to inhibit nocifensive and anxiety-like behavior in chronic pain states only, we have hypothesized that (S)-3,4DCPG could inhibit nociceptive behavior through changes in mGluR8 receptor expression within the CeA in inflammatory pain conditions. Furthermore, we have hypothesized that the (S)-3,4-DCPG antinociceptive effect could be associated with changes in amino acid and serotonin release and the discharge rate of RVM putative pain-regulatory neurons (Fields et al., 2006).

\section{Materials and Methods}

Animals. Male Sprague Dawley rats (Harlan) weighing 250-280 g were housed three per cage under controlled illumination $(12 \mathrm{~h}$ light/dark cycle; light on 6:00 A.M.) and standard environmental conditions (ambient temperature $20-22^{\circ} \mathrm{C}$, humidity $55-60 \%$ ) for at least 1 week before the commencement of experiments. Rat chow and tap water were available ad libitum. All surgery and experimental procedures were performed during the light cycle and were approved by the Animal Ethics Committee of The Second University of Naples. Animal care was in compliance with Italian (D.L. 116/92) and European Commission (O.J. of E.C. L358/1 18/12/86) regulations on the protection of laboratory animals. All efforts were made to reduce both animal numbers and suffering during the experiments.

Carrageenan pain model. The carrageenan model of inflammation was used to examine the effects of (S)-3,4-DCPG on the development of inflammatory hyperalgesia (Perrot et al., 1998). Peripheral inflammation was induced by a single subcutaneous injection of carrageenan $(150 \mu \mathrm{l}$ of $1 \%$ solution) in the plantar surface of the left hindpaw (see Combination of microdialysis and pain state) using a 30 gauge needle while gently restraining the rat.

Microdialysis. Microdialysis experiments were performed in awake and freely moving rats. In brief, rats were anesthetized with pentobarbital $(50 \mathrm{mg} / \mathrm{kg}$, i.p.) and concentric dialysis probes were implanted in the right CeA (2.3 mm caudal to bregma, $7.0 \mathrm{~mm}$ depth and $4.0 \mathrm{~mm}$ lateral to the midline) (Paxinos and Watson, 1986) by using a stereotaxic apparatus. The rationale for the implantation into the right CeA was based on the reported hemispheric lateralization of right $\mathrm{CeA}$ on pain behavior (Carrasquillo and Gereau, 2008; Ji and Neugebauer, 2009; Kolber et al., 2010). Right CeA modulates pain responses independently of whether the right or left paw is injured. Reciprocally, nociceptive information reaches both the left and right amygdala, but it is the right amygdala, unlike the left one, which develops sensitization and processes prolonged nociceceptive inputs (Ji and Neugebauer, 2009). We performed vehicle or drug administrations into the right $\mathrm{CeA}$ and carrageenan injection into the left paw according to these studies and to anatomical and electrophysiological data which suggest a strong contralateral projection of the spino-parabrachio-amygdaloid pain pathway (Gauriau and Bernard, 2002; Neugebauer et al., 2004).

Dialysis probes, were constructed with $25 \mathrm{G}$ ( $0.3 \mathrm{~mm}$ inner diameter, $0.5 \mathrm{~mm}$ outer diameter) stainless steel tubing (A-M Systems). Inlet and outlet cannulae $(0.04 \mathrm{~mm}$ inner diameter, $0.14 \mathrm{~mm}$ outer diameter) consisted of fused silica tubing (Scientific Glass Engineering). The mi- crodialysis probes had a $1.0 \mathrm{~mm}$ long tubular dialysis membrane (Enka AG). Animals were allowed to recover from surgery for 20-24 h, then probes were perfused with artificial CSF (ACSF) (composition in mM: $125 \mathrm{NaCl}, 2.5 \mathrm{KCl}, 1.18 \mathrm{MgCl}_{2}$, and $1.26 \mathrm{CaCl}_{2}$ ) at a rate of $1.5 \mu \mathrm{l} / \mathrm{min}$ using a Harvard Apparatus infusion pump (model 22). After an initial 60 min equilibration period, dialysate samples were collected every $30 \mathrm{~min}$ for $2.5 \mathrm{~h}$ to establish the baseline release of glutamate, GABA, and 5-HT. ACSF or $(S)-3,4$-DCPG $(10 \mu \mathrm{M})$ was perfused into the CeA through the microdialysis probe for $30 \mathrm{~min}$ and thereafter, other $30 \mathrm{~min}$ dialysate samples were collected over the following $3 \mathrm{~h}$. Of the $45 \mu \mathrm{l}$ of microdialysis dialysate samples collected in $30 \mathrm{~min}$, at least $20 \mu \mathrm{l}$ were necessary for 5-HT and $10 \mu \mathrm{l}$ for amino acid measurements.

At the end of the experiments, all the rats were anesthetized with pentobarbital and transcardially perfused with $0.9 \% \mathrm{NaCl}$ solution followed by $10 \%$ formaldehyde solution. The brain was dissected out and fixed in a $10 \%$ formaldehyde solution for $48 \mathrm{~h}$. The brain was cut into $40-\mu \mathrm{m}-$ thick slices and observed under an optical microscope to identify the probe tip. The position of the microdialysis probe in the CeA was histologically confirmed and has been plotted on a standard diagram (Fig. 1A).

Dialysates were analyzed for amino acid content using an HPLC method (Biggs et al., 1992). The system comprised two Gilson pumps (model 303), a C18 reverse-phase column, a Gilson refrigerated autoinjector (model 231) and a Gilson fluorimetric detector (model 121). Dialysates were precolumn derivatized with $o$-pthaldialdehyde (OPA) (10 $\mu \mathrm{l}$ of dialysate $+10 \mu \mathrm{l}$ of OPA) and amino acid conjugates resolved using a gradient separation. The mobile phase consisted of two components: (A) $50 \mathrm{~mm}$ sodium dihydrogen orthophosphate, $\mathrm{pH}$ 5.5, with $20 \%$ methanol and (B) 100\% methanol. Gradient composition was determined using an Apple microcomputer installed with Gilson gradient management software. Mobile phase flow rate was maintained at 1.0 $\mathrm{ml} / \mathrm{min}$. Data were collected by a Dell Corporation PC system 310 interfaced to the detector via a Drew data collection unit. The detection limit of GABA and glutamate in $10 \mu \mathrm{l}$ samples was $\sim 0.5-1$ and $2-3$ pmol, respectively.

Concentration of 5-HT was determined using HPLC equipment fitted with an electrochemical detector. The composition of the mobile phase was $0.15 \mathrm{~mm} \mathrm{NaH}_{2} \mathrm{PO}_{4}, 0.01 \mathrm{~mm}$ octyl sodium sulfate, $0.5 \mathrm{~mm}$ EDTA ( $\mathrm{pH}$ 3.8 adjusted with phosphoric acid) and $12.5 \%$ methanol. The mobile phase was delivered (flow rate: $1 \mathrm{ml} / \mathrm{min}$ ) by a model 590 pump (Waters) into an Ultrasphere $3 \mu \mathrm{m}$ ODS column $(4.6 \mathrm{~mm} \times 7.5 \mathrm{~cm}$; Beckman Ltd). The electrochemical detector was an ESA Coulochem model 5100A with a dual electrode analytical cell (model 5011). The conditioning cell was set at $-0.05 \mathrm{~V}$, electrode 1 at $+0.10 \mathrm{~V}$, and electrode 2 at $+0.25 \mathrm{~V}$ with respect to palladium reference electrodes. The limit of detection for 5-HT was 2-3 fmol per sample injected with a signal-to-noise ratio of 2. The mean dialysate concentration of amino acids and 5-HT in the first five samples before any drug treatment represented the basal release, and results were expressed as a percentage of this value. In particular, the reported value refers to the dialysate fraction in which the highest change in amino acid/5-HT values was observed after drug application. In vitro recovery of the microdialysis probe was $24 \pm 4 \%, 28 \pm 6 \%$, and $32 \pm 4 \%$ for GABA, glutamate, and 5-HT, respectively.

Combination of microdialysis and pain state. Twenty to $24 \mathrm{~h}$ after the surgery for probe implantation rats received the peripheral injection of carrageenan into the plantar surface of the left hindpaw. Rats were immediately placed into the compartments $(22 \times 17 \times 14 \mathrm{~cm}$, length $\times$ with $\times$ height) of the plantar test. Probes were perfused with ACSF and microdialysis was performed together with thermoceptive response measurements. A crucial issue has regarded the possible impact of repeated thermoceptive testing by using the Hargreaves method on 5-HT, glutamate, and GABA release in the CeA. Indeed, several stress sources induce changes in neurotransmitter release in several brain areas (Westerink, 1995) including the amygdala (Kawahara et al., 1993). In one of our previous pilot experiments (unpublished observations) we did not manage to detect changes in the basal neurotransmitter level after repeated thermoceptive stimuli throughout the plantar test with respect to those rats which had not undergone the plantar test. Indeed, it may be possible that the long interval for the perfusate sampling (30 $\mathrm{min})$ compared with the brief interval of thermoceptive stimuli application $(<20 \mathrm{~s})$ did not 


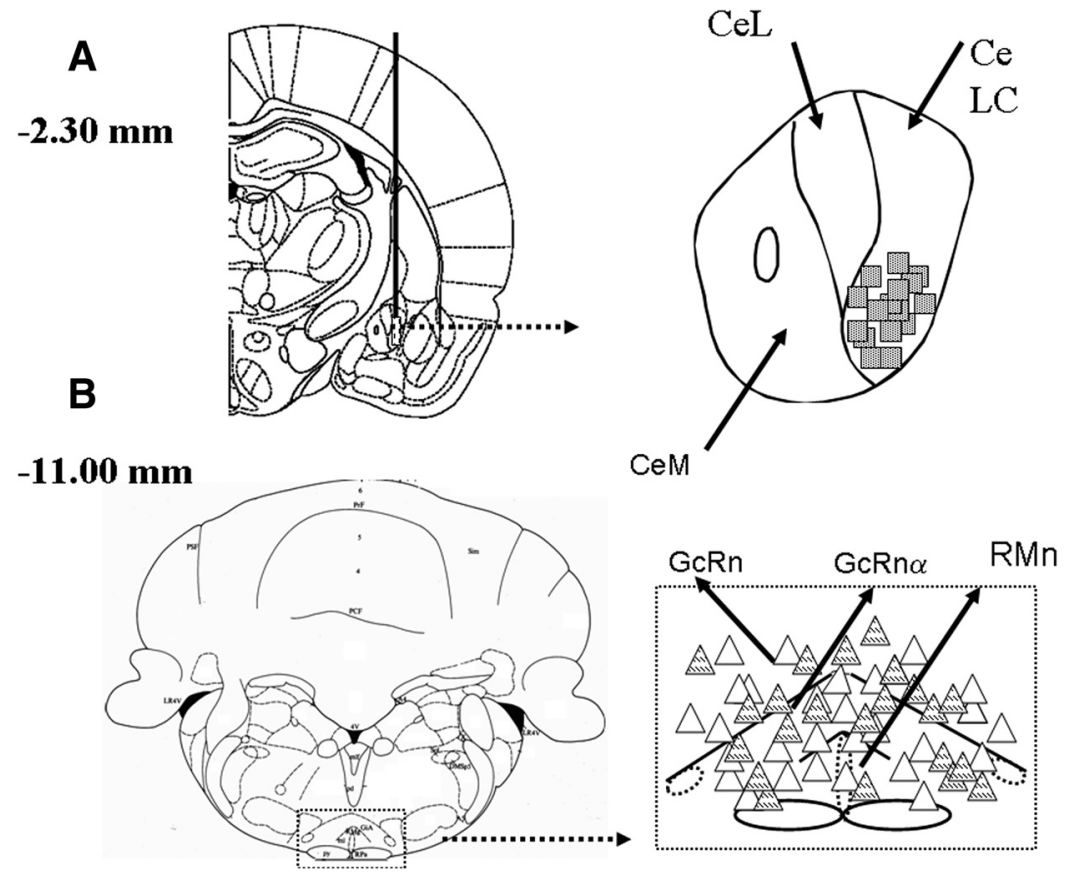

Figure 1. Representative schematic illustration of the microdialysis probe location for drug application into the CeA and electrode positions within RVM. Coronal brain slices containing the microdialysis probes and recording sites were processed after the experiment for histological analysis. The numbers above the illustration show the distance from bregma (Paxinos and Watson, 1986). The probe scheme is illustrated in $\boldsymbol{A}$. The stripped squares indicate probe tips. Triangles indicate electrode tips in the RVM $(\boldsymbol{B})$; in particular, white triangles represent $\mathrm{ON}$ cells and striped, $0 \mathrm{FF}$ cells with overlapping tip positions indicated with a single symbol. CeM, CeL, CeLC refer to medial, lateral, and laterocapsular divisions of the central nucleus of the amygdala, respectively. $\mathrm{RMn}, \mathrm{RG} \mathrm{cn}$, and $\mathrm{RG} \mathrm{cn} \alpha$ refer to nucleus raphe magnus, nucleus reticularis paragigantocellularis, and nucleus reticularis gigantocellularis pars $\alpha$, respectively.

permit us to detect any direct change in neurotransmitter level. Nevertheless, we cannot rule out that exposure to the thermal stimulus might cause alterations in 5-HT or amino acid release during or immediately following the seconds of the noxious stimulus application.

Nociceptive behavior. During microdialysis perfusate collection rats were tested for thermoceptive responses using the Plantar Test Apparatus (Ugo Basile). The radiant heat source consisted of an infrared bulb (Osram halogen-bellaphot bulb; $8 \mathrm{~V}, 50 \mathrm{~W}$ ). A photoelectric cell detected light reflected from the paw and turned off the lamp when paw movement interrupted the reflected light. The paw withdrawal latency was automatically displayed to the nearest $0.1 \mathrm{~s}$; the cutoff time was $20 \mathrm{~s}$ to prevent tissue damage. The latency of nociceptive reaction was measured in seconds every $30 \mathrm{~min}$ (within the time of changing the perfusate samples), starting $30 \mathrm{~min}$ after the peripheral administration of saline or carrageenan. Perfusion with ACSF, (S)-3,4-DCPG, and (RS)- $\alpha$-methylserine-O-phosphate (MSOP) (a group III mGluR antagonist) was delivered through the probe after 5 measurements at 30 min intervals each. When the MSOP was used in combination with (S)-3,4-DCPG, the two drugs were coadministered. Seven further measurements were subsequently taken to monitor druginduced effects by an experimenter who was blind to the treatment. Latency of thermoceptive reaction was expressed as mean \pm SEM in seconds. Groups of 10 rats per treatment were used, with each animal being used for one treatment only.

Surgical preparation for intra-CeA microinjection. As far as the in vivo electrophysiological recording experiments in the anesthetized rats are concerned, the surgical procedure to perform direct intra-CeA administration of (S)-3,4-DCPG or respective vehicle was performed the day before the experiment. Rats were anesthetized with pentobarbital (50 $\mathrm{mg} / \mathrm{kg}$, i.p.), and a 26 gauge, long stainless steel guide cannula (12 mm) was then stereotaxically lowered until its tip was $1.2 \mathrm{~mm}$ above the right CeA (2.3 mm caudal to bregma, $6.2 \mathrm{~mm}$ depth and $4.0 \mathrm{~mm}$ lateral to the midline) by applying the coordinates from the atlas of Paxinos and Watson (1986). The cannula was anchored with dental cement to a stainless steel screw in the skull. We used a stereotaxic apparatus (David Kopf Instruments) with the animal positioned on a homeothermic temperature control blanket (Harvard Apparatus). Direct intra-CeA administration of ACSF vehicle or (S)-3,4-DCPG was conducted through a Hamilton $1 \mu \mathrm{l}$ syringe that was connected to a 33 gauge stainless steel injection cannula by a polyethylene tube. The injection cannula was inserted and extended $1.2 \mathrm{~mm}$ beyond the tip through the guide cannula to reach the CeA. Volumes of $200 \mathrm{nl}$ of vehicle or drug solution were injected into the CeA over a period of $60 \mathrm{~s}$ and the injection cannula was gently removed 2 min later.

RVM extracellular recordings. Twenty to $24 \mathrm{~h}$ after the guide cannula implantation, anesthesia was induced with pentobarbital $(50 \mathrm{mg} / \mathrm{kg}$, i.p.) and maintained with a continuous infusion of propofol $(5-10 \mathrm{mg} / \mathrm{kg} / \mathrm{h}$, i.v.) so that tail flicks were elicited with a constant latency of $4-5 \mathrm{~s}$. Thereafter, rats received the peripheral injection of saline and/or carrageenan into the plantar surface of the left hindpaw. A thermal stimulus was elicited by a radiant heat source of a tail flick unit (Ugo Basile), focused on the rat tail $\sim 3-5 \mathrm{~cm}$ from the tip. The intensity of the radiant heat source was adjusted to $50 \mathrm{~mW}$ (corresponding to $50 \mathrm{~mJ}$ per second) at the beginning of each experiment to elicit a constant tail flick latency. Tail flicks were elicited every $5 \mathrm{~min}$ for at least $15 \mathrm{~min}$ before microinjecting the drug or its vehicle into the CeA. A glass-insulated tungsten filament electrode (3-5 MW) (FHC) was lowered into the RVM using the following stereotaxic coordinates: $2.8-3.3 \mathrm{~mm}$ caudal to lambda, $0.4-0.9$ $\mathrm{mm}$ lateral and $8.9-10.7 \mathrm{~mm}$ depth from the surface of the brain (Paxinos and Watson, 1986) (Fig. $1 B$ ). RVM noxious stimuli-responding neurons were identified by the characteristic OFF cell pause and ON cell burst of activity immediately before tail flick responses (Fields et al., 2006). The recorded signals were amplified and displayed on both analog and a digital storage oscilloscope to ensure that the unit under study was unambiguously discriminated throughout the experiment. Signals were sampled by a CED 1401 interface (Cambridge Electronic Design Ltd.) and analyzed by Spike2 window software (CED, version 4) to create peristimulus rate histograms on-line and to store and analyze digital records of single-unit activity off line. The configuration, shape, and height of the recorded action potentials were monitored and recorded continuously using Spike2 software for on-line and off-line analyses. Once an ON or OFF cell was identified from its background activity, we optimized spike size before all treatments. This study only included neurons whose spike configuration remained constant and could clearly be discriminated from the background activity throughout the entire experiment. By doing so, we were able to determine the activity of only one neuron. In each rat, the activity of only a single neuron was recorded before and after vehicle or drug administration. Ongoing and tail flickrelated activity was recorded $3 \mathrm{~h}$ after the carrageenan (or saline) injection so that the recording coincided with the peak of the hyperalgesia. For each neuron the ongoing activity was obtained by averaging the firing rate (spikes/s) for $50 \mathrm{~s}$ before the tail flick trials (performed every $5 \mathrm{~min}$ ). Moreover, the peak height of the tail flick-related burst (spikes/s) and the onset of the ON cell burst (the time elapsing between the onset of heat application and the increase in the frequency rate, which was at least twofold higher than its baseline) were quantified for the ON cells. The latency to the onset of the pause (time between the onset of heat application and the last action potential) and the duration of the tail flickrelated pause (the time elapsing between the pause onset and the first action potential following tail flick) of OFF cells were also quantified. 
At the end of the experiment, a volume of $200 \mathrm{nl}$ of neutral red $(0.1 \%)$ was injected into the CeA $30 \mathrm{~min}$ before killing the rats with a lethal dose of urethane. Rats were then perfused intracardially with $20 \mathrm{ml}$ of PBS followed by $20 \mathrm{ml}$ of $10 \%$ formalin solution in PBS. The brains were removed and immersed in a saturated formalin solution for $2 \mathrm{~d}$. After fixation, the microinjection and recording sites were identified (Fig. $1 B$ ). The injection sites were ascertained using two consecutive sections (40 $\mu \mathrm{m})$, one stained with cresyl violet to identify the CeA, and the other unstained to determine dye spreading. The recording site was marked with a $20 \mu \mathrm{A}$ DC current applied for $20 \mathrm{~s}$ immediately before the end of the electrophysiological recordings. Only the data from microinjection and drug diffusion sites located within the CeA and those from the recording sites in RVM neurons were included in the results.

Motor coordination. Motor coordination was tested using the accelerating rotarod (model 47700, Ugo Basile) in which rats were required to walk against the motion of a rotating drum with the speed accelerating from 4 to $40 \mathrm{rpm} / \mathrm{min}$ over $300 \mathrm{~s}$. The time on the rod from the start of acceleration until the animal fell from the drum onto the counter-trip plate was recorded. A $300 \mathrm{~s}$ cutoff was used. One training period per day was performed for $2 \mathrm{~d}$ before experiments in which ACSF or the (S)-3,4DCPG (10 $\mu \mathrm{M}, 30 \mathrm{~min}, n=5)$ was perfused through the probe. On the day of testing, normal rats were tested $1 \mathrm{~h}$ before and 1,3 , and $5 \mathrm{~h}$ after intra-CeA ACSF $(n=5)$ or $(S)-3,4-\mathrm{DCPG}(n=5)$ perfusion. Time spent on the rod was taken as the mean \pm SEM in seconds in the consecutive attempts by an experimenter who was blind to the treatment.

In vitro experiment preparation. Two groups of rats $(n=5$ for each group) were treated with an intraplantar dose of $150 \mu \mathrm{l}$ of saline or carrageenan ( $1 \%$ solution); after $4.5 \mathrm{~h}$ (when thermal hyperalgesia had fully developed), they were decapitated and their brains rapidly removed and immersed in ice-cold artificial CSF. A block of tissue containing right CeA was cut using a vibratome (Vibratome 1500, Warner Instruments). A brainstem slice of $600 \mu \mathrm{m}$ was cut throughout the rostral part of the CeA (interaural from $+6.88 \mathrm{~mm}$ to $+6.20 \mathrm{~mm}$ ) (Paxinos and Watson, 1986); after that, CeA was isolated under an optical microscope (M650, Wild Heerbrugg).

$m R N A$ extraction and reverse transcriptase-PCR. The CeA was homogenized and total RNA extracted using an RNA Tri-Reagent (Molecular Research Center Inc.) according to the manufacturer's protocol. The extracted RNA was subjected to DNase I treatment at $37^{\circ} \mathrm{C}$ for $30 \mathrm{~min}$. The total RNA concentration was determined using a UV spectrophotometer. The mRNA levels of the gene for $m G l u R 8$ were measured by reverse transcriptase (RT)-PCR amplification. Sequences for rat $m G l u R 8$ mRNAs from GenBank (DNASTAR Inc.) were used to design primer pairs for RT-PCRs (OLIGO 4.05 software, National Biosciences Inc.). Each RT-PCR was repeated at least four times by an experimenter who was blind to the treatment. A semiquantitative analysis of mRNA levels was performed by the Gel Doc 2000 UV System (Bio-Rad). The measured mRNA levels were normalized with respect to hypoxanthineguanine phosphoribosyltransferase (HPRT), chosen as housekeeping gene, and the gene expression values were expressed as mean of arbitrary units \pm SEM.

Western blotting. The CeA was first minced into small pieces with a blender, and then suspended in lysis buffer (4\% SDS, 20\% glycerol, $10 \%$ 2-mercaptoethanol, $0.004 \%$ bromophenol blue, Tris-HCl, pH 6.8, containing $6 \mathrm{M}$ urea, $50 \mu \mathrm{M} \mathrm{Na} \mathrm{VO}_{4}, 50 \mu \mathrm{M}$ PMSF, Sigma) for protein extraction. Total protein concentration was determined. Each sample was loaded, electrophoresed in an $8 \%$ polyacrylamide gel, and electroblotted onto a nitrocellulose membrane. To detect mGluR8, a goat polyclonal primary antibody (Santa Cruz Biotechnology, Inc) at 1:500 dilution was used. Following incubation, sections were washed and reincubated with secondary antibody solution (donkey anti-goat, IgG-HRP 1:5000; Santa Cruz Biotechnology Inc). GE Healthcare enhanced chemiluminescence (ECL) substrate (Pierce) was used. Protein levels were normalized with respect to the signal obtained with $\beta$-tubulin monoclonal antibodies (Santa Cruz Biotechnology; 1:1000 dilution) chosen as housekeeping protein, and the protein expression values were expressed as mean of arbitrary units \pm SEM.

Immunohistochemistry. Control and carrageenan-treated rats where anesthetized with pentobarbital (50 mg/kg, i.p.) and transcardially per- fused with saline solution followed by $4 \%$ paraformaldehyde in $0.1 \mathrm{M}$ phosphate buffer. The brain was removed, postfixed for $4 \mathrm{~h}$ in the perfusion fixative, cryoprotected for $72 \mathrm{~h}$ in $30 \%$ sucrose in $0.1 \mathrm{M}$ phosphate buffer and frozen in O.C.T. embedding compound. Transverse sections of $15 \mu \mathrm{m}$ were cut using a cryostat and those containing the right CeA were then thaw-mounted onto glass slides. The sections were subsequently incubated for $1 \mathrm{~d}$ at room temperature in a humid chamber with the respective polyclonal antibodies (all diluted in block solution). All sections were processed for rabbit anti-vesicular glutamate transporter-1 (VGLUT1) (1: 500, Synaptic Systems), rabbit anti-vesicular GABA transporter (VGAT) (1:250, Synaptic Systems), goat-anti mGluR8 (1:500, Santa Cruz Biotechnology, Inc). mGluR8 antibody was incubated alone or in combination with $5 \mu \mathrm{g} / \mathrm{ml}$ mGluR8 blocking peptide (Santa Cruz Biotechnology Inc).

Following incubation, sections were washed and incubated for $3 \mathrm{~h}$ with secondary antibody solution (goat anti-rabbit, or donkey anti-goat, IgG-conjugated Alexa Fluor 488 and 568; 1:1000; Invitrogen). Slides were washed, coverslipped with Vectashield mounting medium (Vector Laboratories), and visualized under a Zeiss Axioplan 2 fluorescence microscope. Quantitative analysis of mGluR8-positive profiles was performed by an observer blind to the treatment ( $n=5$ for each treatment). Only the positive profiles counterstained with $4^{\prime}, 6^{\prime}$-diamidino-2-phenylindole dihydrochloride were included in the quantitative analysis.

Drugs. ( S)-3,4-DCPG and MSOP were purchased from Tocris Bioscience. ( $S$ )-3,4-DCPG and MSOP were dissolved in ACSF (vehicle) on the day of the experiment at a concentration 100 times that predicted to be needed in the tissue based on data in the literature (Thomas et al., 2001; Lavialle-Defaix et al., 2006; Marabese et al., 2007b; Palazzo et al., 2008) because of the concentration gradient across the dialysis membrane (Han et al., 2005; Han and Neugebauer, 2005; Ji et al., 2007; Fu and Neugebauer, 2008). The numbers given in this article refer to the drug concentrations in the microdialysis fiber. ACSF administered alone served as a vehicle control. Vehicle or drug solutions were administered into the $\mathrm{CeA}$ at a rate of $1.5 \mu \mathrm{l} / \mathrm{min}$ for $30 \mathrm{~min}$ to establish equilibrium in the tissue. For intra-CeA ( S)-3,4-DCPG microinjection, the dose of $0.1 \mathrm{nmol}$ (in $200 \mu \mathrm{l}$ ) was used according to in vivo study using intracerebral microinjections (Folbergrová et al., 2008).

Data analysis and statistics. All data are given as means \pm SEM. For behavioral, microdialysis, and electrophysiology experiments, two-way ANOVAs for repeated measures followed by Newman-Keuls post hoc test for multiple comparisons have been used to analyze statistical differences between the different treated groups of rats. Comparisons between pretreatment and posttreatment ongoing and tail flick-related cell activity changes were performed by ANOVA for repeated measures. One-way ANOVAs followed by the Newman-Keuls post hoc test were used for biomolecular analysis and protein quantification. For the immunohistochemistry, one-way ANOVA followed by the Tukey test was used. $p$ values $<0.05$ were considered statistically significant.

\section{Results \\ Experimental groups}

A total of 186 adult male rats were used. Extracellular levels of $5-\mathrm{HT}, \mathrm{GABA}$ and glutamate were measured in the CeA in the same animals which were tested for pain responses throughout the plantar test. The behavioral, biochemical and electrophysiological effects of (S)-3,4-DCPG administered into the CeA were investigated in 4 groups of animals: (1) rats receiving intra-CeA ACSF and saline in the plantar surface of the hindpaw (nor/ ACSF), (2) rats receiving intra-CeA ( $S$ )-3,4-DCPG and saline in the plantar surface of the hindpaw (nor/DCPG), (3) rats receiving intra-CeA ACSF and carrageenan into the plantar surface of the hindpaw (carr/ACSF), i.v.) and rats receiving intra-CeA ( $S$ )3,4-DCPG and carrageenan into the plantar surface of the hindpaw (carr/DCPG). For behavioral experiments ( $S$ )-3,4-DCPG (1 and $100 \mu \mathrm{M}, 30 \mathrm{~min}, n=10$ for each dose), MSOP (10 mM, 30 $\min , n=10)$ alone or the latter in combination with $(S)-3,4$ DCPG $(10 \mu \mathrm{M}, 30 \mathrm{~min}, n=10)$ were administered in 
carrageenan-treated rats. MSOP $(10 \mathrm{mM}, 30 \mathrm{~min}, n=10)$ was also administered in normal rats.

\section{Microdialysis}

Serotonin

The values of extracellular 5-HT level in the CeA were measured both before and after ACSF or (S)-3,4-DCPG perfusion in saline or carrageenan-treated rats. The values in fmol $\cdot 20 \mu \mathrm{l}^{-1}$ refer to the mean basal value obtained by averaging the mean dialysate concentration of 5-HT in the first five samples before any treatment. Possible changes after ACSF or (S)-3,4-DCPG were expressed as a percentage of mean basal value for each treatment. In particular, the reported value refers to the dialysate fraction in which the highest change in 5-HT values was observed after drug application. In vitro recovery of the microdialysis probe for 5-HT was $32 \pm 4 \%$. The mean basal value for extracellular 5 -HT within the CeA was $21.9 \pm 1.5 \mathrm{fmol} \cdot 20 \mu \mathrm{l}^{-1}$ (not corrected for probe recovery). Carrageenan did not produce any change in extracellular 5-HT within the CeA. ( $)$-3,4-DCPG (10 $\mu \mathrm{M}, 30 \mathrm{~min}$, $n=10$ ) per se had no effect on 5 -HT levels, but did induce a robust increase in extracellular 5-HT in rats given carrageenan (178.1 $\pm 8 \%$ of the predrug baseline, $p<0.01$, two-way ANOVA/Newman-Keuls post hoc test) compared with carr/ ACSF rats (Fig. $2 A$ ).

\section{Glutamate}

The values of extracellular level of glutamate in CeA were measured in pmol $\cdot 10 \mu \mathrm{l}^{-1}$. In vitro recovery of the microdialysis probe for glutamate was $28 \pm 6 \%$. The mean basal value for glutamate within CeA was $32.8 \pm 2 \mathrm{pmol} \cdot 10 \mu \mathrm{l}^{-1}$. Neither carrageenan nor $(S)$-3,4-DCPG per se changed extracellular glutamate within the amygdala. However $(S)-3,4-$ DCPG $(10 \mu \mathrm{M}, 30$ $\min , n=10)$ produced a robust increase in extracellular glutamate in rats given carrageenan ( $189 \pm 17 \%$ of the predrug baseline, $p<0.01$, two-way ANOVA/Newman-Keuls post hoc test) compared with carr/ACSF rats (Fig. $2 B$ ).

\section{GABA}

In vitro recovery of the microdialysis probe for GABA was $24 \pm$ $4 \%$. The mean basal values (not corrected for probe recovery) of extracellular GABA level in CeA were $0.96 \pm 0.44 \mathrm{pmol} \cdot 10 \mu \mathrm{l}^{-1}$. Intra-CeA perfusion with ACSF, ( $S$ )-3,4-DCPG or intraplantar carrageenan injection did not change CeA extracellular GABA. (S)-3,4-DCPG $(10 \mu \mathrm{M}, 30 \mathrm{~min}, n=10)$ perfused through the probe into the CeA induced a significant ( $48 \pm 9 \%$ of the predrug baseline, $p<0.05$, two-way ANOVA/Newman-Keuls post hoc test) decrease of the extracellular GABA level in rats receiving carrageenan into the plantar surface of the hindpaw compared with carr/ACSF rats (Fig. 2C).

\section{Plantar test}

The intraplantar administration of carrageenan induced a significant and long-lasting decrease in thermal withdrawal latency with a peak at $240 \mathrm{~min}$ after the injection of carrageenan $(1.9 \pm$ $0.4 \mathrm{~s}, n=10, p<0.01$, two-way ANOVA/Newman-Keuls post hoc test) compared with nor/ACSF rats (Fig. 3A). No significant changes were observed in normal rats after intra-CeA $(S)$-3,4DCPG $(10 \mu \mathrm{M}, 30 \mathrm{~min}, n=10)$ perfusion $(8.8 \pm 0.8 \mathrm{~s}, n=10)$. The lower dose of $(S)$-3,4-DCPG $(1 \mu \mathrm{M}, 30 \mathrm{~min}, n=10)$ significantly changed the thermal withdrawal latency only $1 \mathrm{~h}$ after the intra-CeA perfusion ( $3.5 \pm 0.6 \mathrm{~s}, n=10, p<0.05$, two-way ANOVA/Newman-Keuls post hoc test) in rats receiving carrageenan compared with carr/ACSF animals (Fig. 3B). Intra-CeA perfusion with $(S)-3,4-\mathrm{DCPG}(10 \mu \mathrm{M}, 30 \mathrm{~min}, n=10)$ signifi-
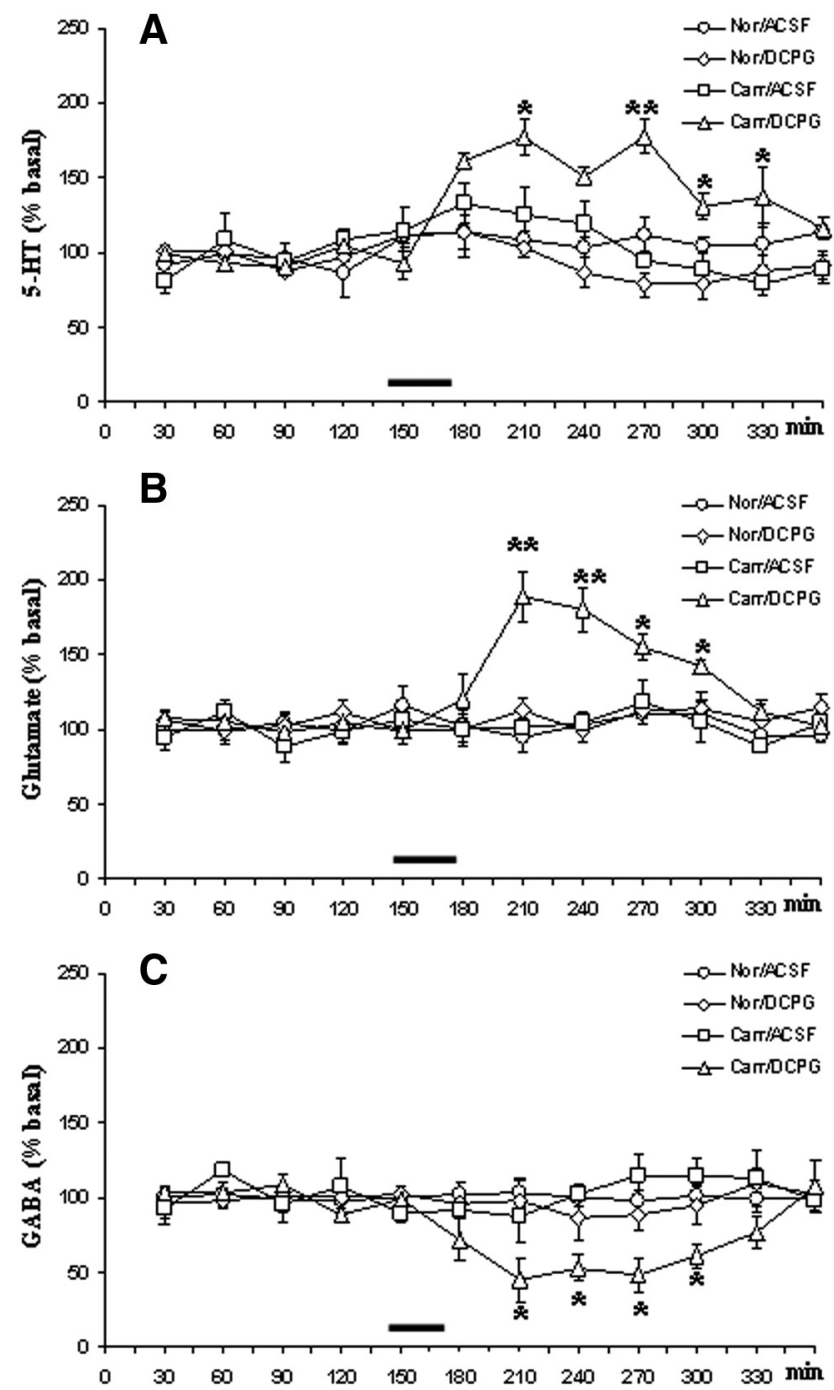

Figure 2. $\quad A-C$, The effects of vehicle (ACSF) or (S)-3,4-DCPG (10 $\mu \mathrm{m}$ referred to the microdialysis fiber, $30 \mathrm{~min}, n=10$ ) perfusion into the CeA on release of 5 -HT $(\boldsymbol{A})$, glutamate $(\boldsymbol{B})$, and GABA $(C)$ in rats receiving saline (Nor) or carrageenan (Carr) into the hindpaw. The values of extracellular 5-HT, glutamate, and GABA level in the CeA were expressed as a percentage of the mean basal value and were measured before and after ACSF or (S)-3,4-DCPG perfusion into the CeA as indicated by the bar. Each point represents the mean \pm SEM of 10 animals per group; ${ }^{*} p<0.05,{ }^{* *} p<0.01$, significant differences vs Carr/ACSF (two-way ANOVA/ Newman-Keuls).

cantly increased the thermal withdrawal latency $(5.2 \pm 0.8 \mathrm{~s}, n=$ $10, p<0.01$, two-way ANOVA/Newman-Keuls post hoc test) in rats receiving the intraplantar administration of carrageenan (Fig. $3 A, B$ ) compared with carr/ACSF animals. The highest dose of ( $S)$-3,4-DCPG (100 $\mu \mathrm{M}, 30 \mathrm{~min}, n=10)$ significantly increased thermal withdrawal latency $(6.8 \pm 0.6 \mathrm{~s}, n=10, p<0.01$, two-way ANOVA/Newman-Keuls post hoc test) compared with carr/ACSF rats (Fig. 3B). Thermal withdrawal latency after $(S)$ 3,4-DCPG (10 and $100 \mu \mathrm{M})$ in carrageenan-treated rats was not statistically different ( $p>0.05$, two-way ANOVA) from the latency in nor/ACSF animals (Fig. 3A). The antinociceptive effect of intra-CeA perfusion with ( $S$ )-3,4-DCPG (10 $\mu \mathrm{M}, 30 \mathrm{~min}, n=$ $10)$ in carrageenan-treated rats was antagonized when MSOP (10 $\mathrm{mM}, 30 \mathrm{~min}, n=10$ ), a group III mGluR antagonist, was coadministered $(p<0.05$, two-way ANOVA/Newman-Keuls post hoc test) (Fig. $4 A$ ). MSOP alone ( $10 \mathrm{~mm}, 30 \mathrm{~min}, n=10)$ did not change thermal withdrawal latency in normal and carrageenan- 
A

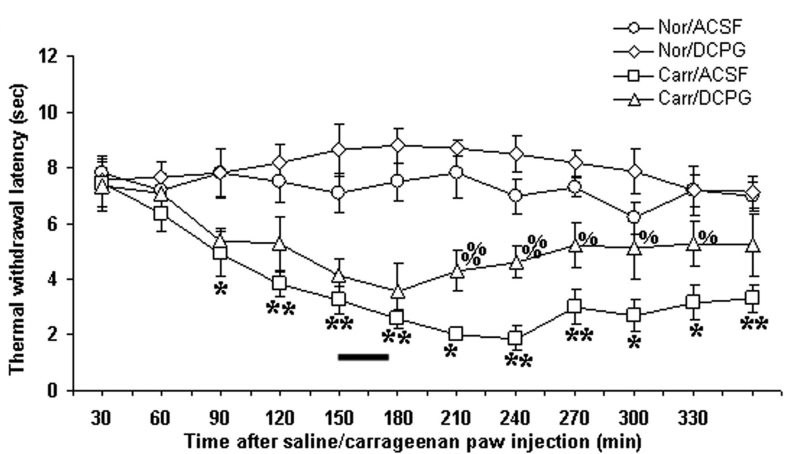

B

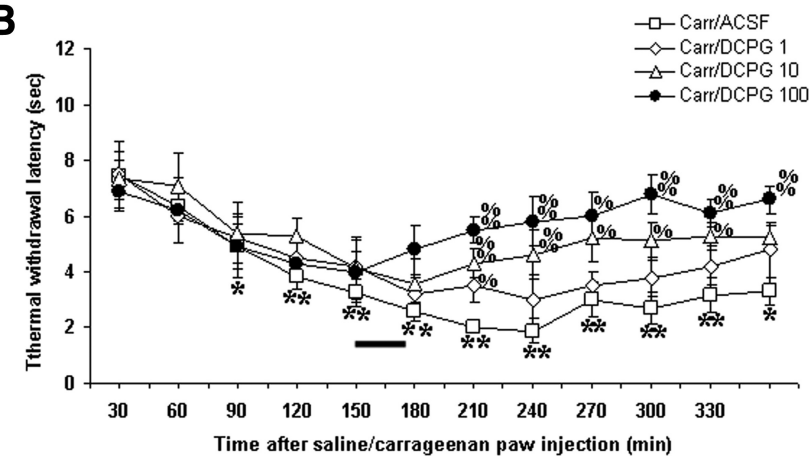

Figure 3. Thermal withdrawal latency (in seconds) was measured 30 min after the injection of saline (150 $\mu$ l of saline, Nor) or carrageenan (1\%, $150 \mu \mathrm{l}$, Carr) into the hindpaw. A shows the effect of ACSF or (S)-3,4-DCPG (10 $\mu \mathrm{m}$ referred to the microdialysis fiber, $30 \mathrm{~min}, n=10$ ) perfused into the CeA, as indicated by the bar. $\boldsymbol{B}$ shows the effect of ACSF or three doses of (S)-3,4-DCPG $(1,10$, and $100 \mu \mathrm{m}$ referred to the microdialysis fiber, $30 \mathrm{~min}, n=10$ for each dose) perfused into the $(e A$, as indicated by the bar, in rats receiving carrageenan. Carrageenan injection induced a reduction in thermal withdrawal latency with a peak at $240 \mathrm{~min}$ in rats receiving ACSF into the probe. Thermal withdrawal latency significantly increased after $(S)-3,4-$ DCPG $(1,10$, and $100 \mu \mathrm{m}$ referred to the microdialysis fiber, $30 \mathrm{~min}, n=10)$ in the rats receiving the peripheral injection of carrageenan into the hindpaw. Normal rats receiving (S)-3,4-DCPG (10 $\mu \mathrm{m}$ referred to the microdialysis fiber, $30 \mathrm{~min}, n=10$ ) showed no significant changes in thermal withdrawal latency. Significant differences *vs Nor/ACSF, ${ }^{*}$ vs Carr/ACSF. $p$ values $<$ 0.05 or 0.01 have been indicated by a single or double symbol, respectively (two-way ANOVA/Newman-Keuls).

treated rats with respect to nor/ACSF and carr/ACSF groups of rats, respectively (Fig. $4 B$ ). Moreover, no changes have been observed in the contralateral paw in ACSF, (S)-3,4-DCPG and MSOP-treated animals (data not shown).

\section{Rotarod}

In the rotarod test, neither ACSF $(241 \pm 17 \mathrm{~s})$ nor the $(S)-3,4-\mathrm{DCPG}$ $(10 \mu \mathrm{M}, 30 \mathrm{~min}, n=10)(239 \pm 13 \mathrm{~s})$ affected performance in normal animals compared with ACSF and ( $S$ )-3,4-DCPG preadministration latency ( $246 \pm 15$ and $235 \pm 12 \mathrm{~s}$, respectively).

\section{Ongoing activity of RVM ON and OFF cells}

The results were based on RVM neurons (one cell recorded from each animal per treatment) at a depth 9900-10,955 $\mu \mathrm{m}$ from the surface of the brain. All recorded neurons, identified as OFF cells by the characteristic pause induced by the tail flick trail, were spontaneously active and discharged with a mean frequency of $7.9 \pm 0.6$ spikes/s (Fig. $5 B$ ).

Neurons identified as ON cells by a burst of activity just before tail flick responses were spontaneously active in $31.2 \%$ of the cases and inactive in the remaining cases. ON cells with spontaneous activity were chosen to better characterize the activity of this $\mathrm{ON}$ cell subgroup and to consider postdrug changes in their
A
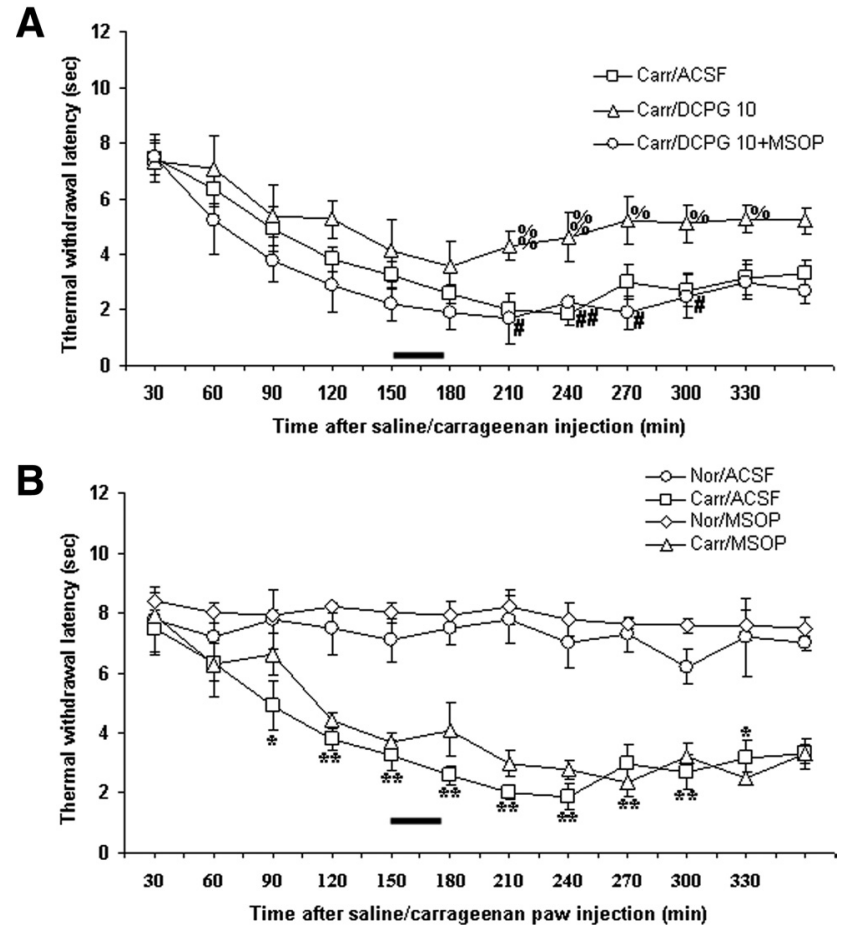

Figure 4. Thermal withdrawal latency (in seconds) was measured 30 min after the injection of saline (150 $\mu$ l saline, Nor) or carrageenan (1\%, $150 \mu \mathrm{l}$, Carr) into the hindpaw. $\boldsymbol{A}$ shows the effect of ACSF, (S)-3,4-DCPG (10 $\mu \mathrm{m}$ referred to the microdialysis fiber, $30 \mathrm{~min}, n=10)$ or the latter in combination with MSOP (10 mM referred to the microdialysis fiber, $30 \mathrm{~min}, n=10$ ) perfused into the $C$ eA, as indicated by the bar, in rats receiving carrageenan. $B$ shows the effect of ACSF or MSOP (10 mm referred to the microdialysis fiber, $30 \mathrm{~min}, n=10$ ) perfused into the $\mathrm{CeA}$, as indicated by the bar, in rats receiving saline or carrageenan. Significant differences ${ }^{*} \mathrm{vs}$ Nor/ACSF, ${ }^{\%}$ vs Carr/ACSF, and "vs Carr/DCPG. $p$ values $<0.05$ or 0.01 have been indicated by a single or double symbol, respectively (two-way ANOVA/Newman-Keuls).

spontaneous activity. The population of ON cells with spontaneous activity had a mean frequency of $7.08 \pm 0.6$ spikes/s (Fig. $5 A$ ).

Microinjection of ACSF into the CeA did not change the spontaneous activity of either ON ( $6.9 \pm 0.6$ spikes/s, $n=7)$ or OFF cells (7.8 \pm 0.5 spikes/s, $n=7)$ in either normal or carrageenan-treated rats. Microinjections of ( $S)$-3,4-DCPG (0.1 $\mathrm{nmol}$ ) into the CeA did not change the spontaneous activity of either ON (6.6 \pm 0.5 spikes/s, $n=7)$ or OFF cells $(7.6 \pm 0.8$ spikes/s, $n=7$ ) in normal rats but caused a decrease in the firing activity of the ON cells, which was significant between 25 and 60 $\mathrm{min}$, reaching a maximum value at $55 \mathrm{~min}$ after drug microinjection in rats receiving carrageenan (1.89 \pm 1.09 spikes/s, $n=7$, $p<0.01$, two-way ANOVA/Newman-Keuls post hoc test) compared with carr/ACSF rats (Fig. 5A). The same treatment produced a very rapid increase in the firing activity of the OFF cells, which was significant between 10 and $60 \mathrm{~min}$ and maximum at 20 min after $(S)-3,4-$ DCPG $(0.1 \mathrm{nmol})$ treatment $(14.95 \pm 1.44$ spikes/s, $n=7, p<0.01$, two-way ANOVA/Newman-Keuls post hoc test) in rats receiving carrageenan compared with the carr/ ACSF group (Fig. 5B).

\section{Tail flick-related ON and OFF cell activity}

Microinjection of vehicle did not change the $\mathrm{ON}$ cell burst $(14.4 \pm 0.8$ spikes/s) nor the OFF cell pause $(7.38 \pm 1 \mathrm{~s})$ (Fig. $6 A, B)$.

Intra-CeA microinjection of $(S)-3,4-D C P G(0.1 \mathrm{nmol})$ did not change the ON cell burst $(14.1 \pm 0.4$ spikes/s) nor the OFF cell pause $(7.1 \pm 0.1 \mathrm{~s})$ in control rats while it decreased the $\mathrm{ON}$ 
A

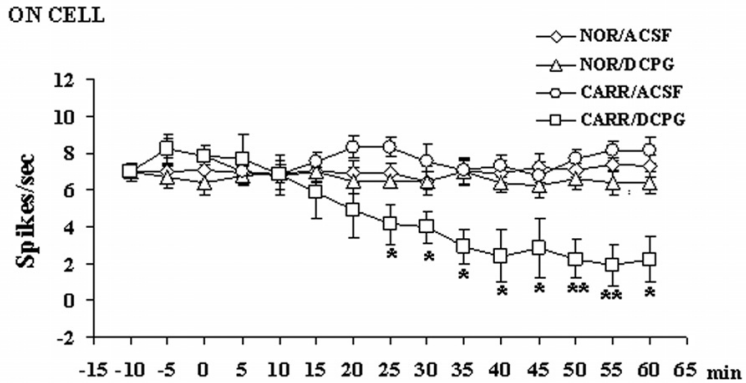

B

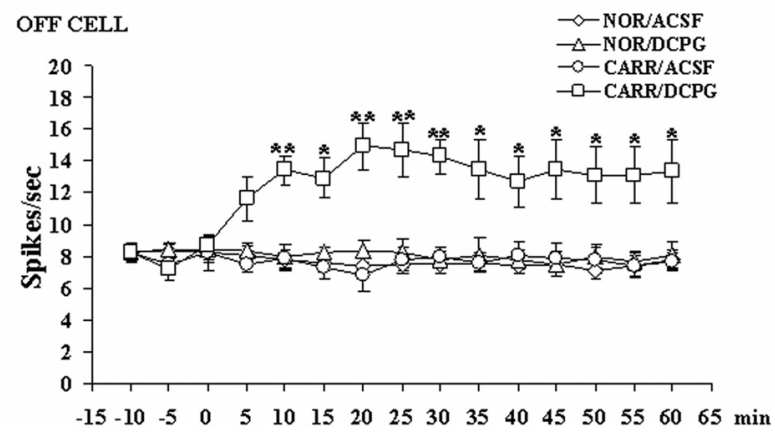

Figure 5. $\boldsymbol{A}, \boldsymbol{B}$, The effects of intra-CeA microinjections of vehicle (ACSF) or (S)-3,4DCPG $(0.1 \mathrm{nmol})$ on the spontaneous firing of RVM ON $(\boldsymbol{A})$ or OFF $(B)$ cells in rats receiving saline (Nor) or carrageenan (Carr) into the hindpaw. Microinjections of vehicle or drug solution $(200 \mathrm{nl})$ were performed at time 0 . Each point represents the mean \pm SEM of 7 neurons. Significant differences vs Carr/ACSF at ${ }^{*} p<0.05$ or ${ }^{* *} p<0.01$, respectively (two-way ANOVA/Newman-Keuls).

cell burst (3.6 \pm 1 spikes/s, $p<0.01$, two-way ANOVA/Newman-Keuls post hoc test) and the duration of the OFF cell pause (3.1 $\pm 1.1 \mathrm{~s}, p<0.01$, two-way ANOVA/Newman-Keuls post hoc test) in rats receiving carrageenan (Fig. $6 A, B$ ) compared with the carr/ACSF group. Moreover, this treatment increased the onset of the tail flick-related ON cell firing (11.01 $\pm 0.5 \mathrm{~s}$ spikes/s, $p<$ 0.05, two-way ANOVA/Newman-Keuls post hoc test) as well as the onset of the OFF cell pause $(8.9 \pm 0.5 \mathrm{~s}, p<0.05$, two-way ANOVA/Newman-Keuls post hoc test) compared with the carr/ ACSF group.

\section{Gene expression of $\mathrm{mGluR8}$}

The semiquantitative analysis of mRNA levels within the CeA measured by RT-PCR amplification showed a significant increase in the $m G l u R 8$ gene in the carrageenan-treated rats (mean of arbitrary units $\pm \mathrm{SEM}, 183 \pm 9.4 \%, n=5 p<0.01$, one-way ANOVA/Newman-Keuls) compared with saline-treated ones (mean of arbitrary units \pm SEM, $100 \pm 8.8 \%, n=5$ ) (Fig. $7 B$ ).

\section{Western blotting}

Western blot analysis showed a significant increase in mGluR8 protein levels in the right $\mathrm{CeA}$ in rats receiving carrageenan (mean of arbitrary units \pm SEM: $136 \pm 6 \%, n=5, p<0.05$, one-way ANOVA/Newman-Keuls) compared with those receiving the same volume of saline into the left hindpaw (mean of arbitrary units \pm SEM, $100 \pm 9.4 \%, n=5$ ) (Fig. 7C).

\section{Immunohistochemistry}

Immunohistochemical analysis revealed increased staining for mGluR8 in the CeA after treatment with carrageenan (33.4 \pm 0.8 , $n=5, p<0.01$, one-way ANOVA/Tukey test) compared with rats receiving a saline injection $(13.2 \pm 1.8, n=5)$ (Fig. $6 D$, top). Moreover, we observed a shift in VGAT-positive profiles from
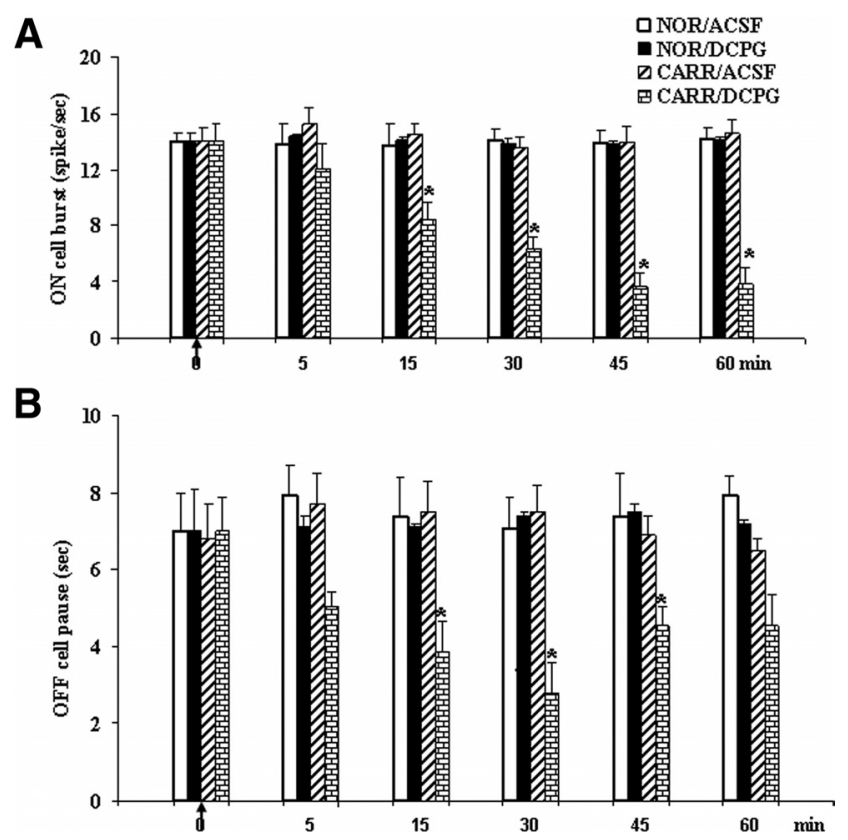

Figure 6. $\quad A, B$, The effects of microinjections of vehicle (ACSF) or (S)-3,4-DCPG $(0.1 \mathrm{nmol})$ on tail-flick induced RVM ON burst of firing $(\boldsymbol{A})$ or $0 \mathrm{FF}$ cell pause duration $(\boldsymbol{B})$ in rats receiving saline (Nor) or carrageenan (Carr) into the hindpaw. Microinjections of vehicle or drug solution (200 nl) were performed at time 0 . Each histogram represents the mean \pm SEM of 7 recorded neurons per group. Significant differences vs carr/ACSF at ${ }^{*} p<0.05$ and ${ }^{* *} p<0.01$, respectively (two-way ANOVA/Newman-Keuls).

the cell perikarya to the dendrites (referred to Chaudhry et al., 1998) (Fig. 7D). Interestingly, we evaluated the location of the mGluR8 through a double-staining approach which shows wide VGAT counterstaining while few positive profiles were colabeled with VGLUT1 after treatment with carrageenan, suggesting that the mGluR8 may act as a heteroreceptor (Marabese et al., 2007b) (Fig. 7D, bottom). Negative control by using the secondary antibodies alone or blocking peptide coincubation did not reveal any positive profiles. The blocking peptide strategy was preferred to mGluR8 knock-out mice so as to avoid the use of different species (Fig. 7D, insets in top).

\section{Discussion}

This study has investigated the role of mGluR8 in the CeA on nociception and on 5-HT, GABA, and glutamate release in healthy and in carrageenan-treated rats. (S)-3,4-DCPG, a selective mGluR8 agonist (Thomas et al., 2001), dose-dependently reduces thermal hyperalgesia in rats receiving carrageenan. This effect was prevented by coadministering MSOP, a group III mGluRs antagonist. The $(S)-3,4-\mathrm{DCPG}$ antinociceptive effect in carrageenan-treated rats was associated with an increase in 5-HT and in glutamate and a decrease in GABA release within CeA.

It has been already shown that $(S)-3,4-D C P G$ has antinociceptive and anti-anxiety properties within the CeA (Palazzo et al., $2008)$ in an arthritis pain model, whereas it proved to be ineffective in normal conditions. Moreover, $(S)-3,4$-DCPG induced antinociception in several pain models, either when systemically or intra-PAG administered (Marabese et al., 2007a). In particular, intra-PAG mGluR8 stimulation determined: (1) an increase in glutamate and a decrease in GABA, antagonized by MSOP (Marabese et al., 2005); (2) a decrease in formalin and carrageenan-induced pain, blocked by intra-PAG MSOP (Marabese et al., 2007a); (3) the activation of the antinociceptive OFF cells and the inhibition of the pronociceptive ON cells within 
RVM (Marabese et al., 2007b). These findings support a potential for the mGluR8 agonist in alleviating chronic pain through the stimulation of the PAGRVM descending system.

Lines of evidence indicate the $\mathrm{CeA}$ as being part of antinociceptive descending system including PAG, RVM, and spinal cord (Helmstetter, 1992; Heinricher and McGaraughty, 1999; Millan, 1999; Fields, 2000; Rhudy and Meagher, 2000; Gauriau and Bernard, 2002) whose lesions reduced or abolished analgesia (Helmstetter, 1992; Helmstetter and Bellgowan, 1993; Fox and Sorenson, 1994; Watkins et al., 1998; Crown et al., 2000). Involvement of the amygdala in pain inhibition is, however, counterbalanced by just as many studies which have established a contribution of the $\mathrm{CeA}$ in pain facilitation (Manning, 1998; Crown et al., 2000; Greenwood-Van Meerveld et al., 2001).

To investigate the effect of mGluR8 receptor stimulation within the antinoceptive descending pathway further, the effect of intra-CeA microinjections of $(S)$ 3,4-DCPG on ON and OFF cell population of RVM (Fields et al., 2006) was also investigated. Within the RVM, ON cells, which show a burst just before a nociceptive reflex (Fields et al., 1983), have a facilitatory effect, whereas OFF cells (which show a pause just before a nociceptive reflex) have an inhibitory effect on nociception (Fields et al., 1983, 2006; Heinricher and Tortorici, 1994; Neubert et al., 2004; Kincaid et al., 2006). The RVM activity is under the influence of the CeA (McGaraughty and Heinricher, 2002; Ansah et al., 2009). The pain-modulating effect originating in and/or relying on the CeA may be mediated directly by the RVM (Hermann et al., 1997) or indirectly through the PAG to the RVM (Rizvi et al., 1991). Consistently, we found that intra-CeA microinjection of (S)-3,4-DCPG increased $\mathrm{OFF}$ and inhibited $\mathrm{ON}$ cell ongoing activity in rats receiving carrageenan. (S)-3,4-DCPG also reduced tail flick-induced ON cell burst and OFF cell pause and increased the onset of both ON cell burst and OFF cell pause in the same animals. ( S)-3,4-DCPG instead failed to change RVM neural activity in control rats.

The analysis of mGluR8 gene, protein, and immunohistochemistry suggest an increased expression of mGluR8 in the CeA in carrageenan-treated rats. These mGluR8-positive profiles show wide VGAT counterstaining after carrageenan, indicating that the mGluR8 is overexpressed after inflammatory pain on GABAergic interneurons within the CeA. This increased mGluR8 expression in carrageenan-treated animals did not appear to be associated with any changes in neurotransmitter release and/or RVM cell activity. Since group II/III mGluRs modulate glutamatergic and GABAergic neurotransmission (Schoepp, 2001) one might expect that any change in mGluR8 expression after carrageenan would be accompanied by some changes in neurotransmitter release and in downstream RVM ON and OFF cell activity. Even if microdialysis does not permit accurate measurement of release from synapses, the unchanged 5-HT, GABA, and glutamate level after carrageenan could suggest the corecruitment of the other mGluR subtypes such as mGluR7, whose opposite ac- tion on glutamate release, RVM cell activity and nociception with respect to mGluR8 has been reported (Marabese et al., 2007a,b; Palazzo et al., 2008). Thus, the opposing role of some different mGluRs might be associated with dual glutamate action in modulating chronic pain: from a worsening (Neugebauer et al., 2003; Neugebauer et al., 2004) to an inhibition (Millecamps et al., 2007) of pain. To further clarify the significance of the mGluR8 increase after carrageenan we have performed experiments where MSOP, perfused into the CeA, did not change threshold in either healthy or carrageenan-treated rats. This finding could indicate in both normal and inflammatory pain conditions: (1) the absence of a tonic role of mGluR8, even if overexpressed, whose blockade did not change thermoceptive response; (2) two counteracting tonic actions exerted by different group III mGluRs subtypes, whose blockade leads to the annulment of the effect and (3) an adaptive process in CeA functioning where a balance between excitatory/inhibitory influences regulates pain processing. The diverse effects induced by intra-CeA/PAG group III mGluR blockade on nociceptive responses reported so far vary from facilitation (Palazzo et al., 2001; Li and Neugebauer, 2006), inhibition (Maione et al., 1998; Berrino et al., 2001) to a lack of effect (Marabese et al., 2007b). Thus, further investigation, possibly with a selective mGluR8 antagonist, appears necessary to better characterize mGluR8 role, which likely plays a different (or opposite) role with respect to other group III mGluRs within the $\mathrm{CeA}$ and/or PAG in normal and inflammatory pain conditions.

Notwithstanding that we were unable to functionally differentiate the neuron terminals on which mGluR8 was stimulated by ( $S$ )-3,4-DCPG in carrageenan-treated rats we observed: (1) an increased expression of $m G l u R 8$ gene; (2) an increased expres- 
sion of mGluR8 protein; (3) an increase in mGluR8 staining associated with VGAT-positive profiles; (4) a (S)-3,4-DCPGinduced GABA decrease and glutamate and 5-HT increase and (5) a (S)-3,4-DCPG-induced decrease and increase in ON and OFF cell activity, respectively. These findings suggest that increased mGluR8 expression in carrageenan-treated rats might preferentially occur on GABAergic terminals within the CeA, consistently with our previous evidence within the PAG (Marabese et al., 2005). The increase in 5-HT and glutamate after $(S)$ 3,4-DCPG, would seem to be unexpected, as mGluR8 is a presynaptic receptor associated with neurotransmitter release inhibition (Schaffhauser et al., 1998; Cartmell and Schoepp, 2000; Schoepp, 2001).

An increase in glutamate due to mGluR8 stimulation and an increase in 5-HT after group III mGluR stimulation have been observed within the PAG in our previous studies (Maione et al., 1998; Marabese et al., 2005) and by mGluR4a stimulation within the entorhinal cortex in another (Evans et al., 2000). Furthermore, it has also been shown that a mixed mGluR8 agonist and AMPA receptor antagonist, has an excitatory action on the striatopallidal pathway by inhibiting GABA release (Mörl et al., 2002; Ossowska et al., 2007), the mGluR8 being located on glutamatergic and GABAergic synapses at this level (Bradley et al., 1999; Wittmann et al., 2001). Since GABA release proved to be inhibited by (S)-3,4DCPG after carrageenan in this study, the increase in glutamate and 5-HT observed here may therefore be a consequence of GABAergic depression. Moreover, mGluR8 stimulation in the CeA, similar to the PAG, by inhibiting GABAergic tone, would in turn, disinhibit OFF cells and inhibit ON cells in the RVM (Behbehani and Fields, 1979; de Novellis et al., 2005; Maione et al., 2006; Marabese et al., 2007b). These electrophysiological outcomes are consistent with antinociception. However, the involvement and/or contribution of mGluR8 stimulation on glutamatergic terminals, which could have generated opposite effects, cannot be ruled out.

The overexpression of mGluR8 within the CeA after carrageenan is consistent with the effect of (S)-3,4-DCPG in chronic pain conditions and a lack of efficacy in normal states. Unlike broad spectrum group III receptor agonists, which inhibited not only pain-related plasticity but also baseline transmission in the amygdala (Han et al.,2004; Li and Neugebauer, 2006), mGluR8 requires pathological pain conditions to generate antinociception (Marabese et al., 2007a; Palazzo et al., 2008). Accordingly, (S)-3,4-DCPG did not affect baseline synaptic transmission in hippocampal slices (Ayala et al., 2008) and failed to modify anxiety-like behavior in normal rats when administered either in the CeA (Palazzo et al., 2008) or in the basolateral amygdala (Stachowicz et al., 2005). Consistently, (S)-3,4-DCPG did not change the neurotransmitter release, RVM cell activity or thermal threshold in physiological conditions.

In conclusion, the study shows an antinociceptive effect of the $(S)$-3,4-DCPG locally applied in the CeA in carrageenaninduced inflammatory pain. This effect is associated with an increase in 5-HT and glutamate, a reduction in GABA release and the inhibition of the ON- and enhancement of the OFF cell activity within the RVM. The increased $m G l u R 8$ gene and protein expression together with increased immunostaining on VGAT-positive perikarya and dendrites observed in carrageenan-induced inflammatory pain provides evidence that within the CeA, mGluR8 may represent a target for inducing analgesia in chronic pain conditions associated with affective disorders.

\section{References}

Ansah OB, Gonçalves L, Almeida A, Pertovaara A (2009) Enhanced pronociception by amygdala group I metabotropic glutamate receptors in nerve-injured animals. Exp Neurol 216:66-74.

Ayala JE, Niswender CM, Luo Q, Banko JL, Conn PJ (2008) Group III mGluR regulation of synaptic transmission at the SC-CA1 synapse is developmentally regulated. Neuropharmacology 54:804-814.

Behbehani MM, Fields HL (1979) Evidence that an excitatory connection between the periaqueductal gray and nucleus raphe magnus mediates stimulation produced analgesia. Brain Res 170:85-93.

Bernard JF, Bester H, Besson JM (1996) Involvement of the spinoparabrachio-amygdaloid and -hypothalamic pathways in the autonomic and affective emotional aspects of pain. Prog Brain Res 107:243-255.

Berrino L, Oliva P, Rossi F, Palazzo E, Nobili B, Maione S (2001) Interaction between metabotropic and NMDA glutamate receptors in the periaqueductal grey pain modulatory system. Naunyn-Schmiedebergs Arch Pharmacol 364:437-443.

Biggs CS, Pearce BR, Fowler LJ, Whitton PS (1992) The effect of sodium valproate on extracellular GABA and other amino acids in the rat ventral hippocampus: an in vivo microdialysis study. Brain Res 594:138-142.

Bourgeais L, Gauriau C, Bernard JF (2001) Projections from the nociceptive area of the central nucleus of the amygdala to the forebrain: a PHA-L study in the rat. Eur J Neurosci 14:229-255.

Bradley SR, Standaert DG, Levey AI, Conn PJ (1999) Distribution of group III mGluRs in rat basal ganglia with subtype-specific antibodies. Ann N Y Acad Sci 868:531-534.

Carrasquillo Y, Gereau RW 4th (2008) Hemispheric lateralization of a molecular signal for pain modulation in the amygdala. Mol Pain 4:24-28.

Cartmell J, Schoepp DD (2000) Regulation of neurotransmitter release by metabotropic glutamate receptors. J Neurochem 75:889-907.

Chaudhry FA, Reimer RJ, Bellocchio EE, Danbolt NC, Osen KK, Edwards RH, Storm-Mathisen J (1998) The vesicular GABA transporter, VGAT, localizes to synaptic vesicles in sets of glycinergic as well as GABAergic neurons. J Neurosci 18:9733-9750.

Ciranna L (2006) Serotonin as a modulator of glutamate- and GABAmediated neurotransmission: implications in physiological functions and in pathology. Curr Neuropharmacol 4:101-114.

Crown ED, King TE, Meagher MW, Grau JW (2000) Shock-induced hyperalgesia: III. Role of the bed nucleus of the stria terminalis and amygdaloid nuclei. Behav Neurosci 114:561-573.

Curzon G (1988) Serotonergic mechanisms of depression. Clin Neuropharmacol Suppl 2:S11-S20.

de Novellis V, Mariani L, Palazzo E, Vita D, Marabese I, Scafuro M, Rossi F, Maione S (2005) Periaqueductal grey CB1 cannabinoid and metabotropic glutamate subtype 5 receptors modulate changes in rostral ventromedial medulla neuronal activities induced by subcutaneous formalin in the rat. Neuroscience 134:269-281.

Evans DI, Jones RS, Woodhall G (2000) Activation of presynaptic group III metabotropic receptors enhances glutamate release in rat entorhinal cortex. J Neurophysiol 83:2519-2525.

Fields HL (2000) Pain modulation: expectation, opioid analgesia and virtual pain. Prog Brain Res 122:245-253.

Fields HL, Bry J, Hentall I, Zorman G (1983) The activity of neurons in the rostral medulla of the rat during withdrawal from noxious heat. J Neurosci 3:2545-2552.

Fields HL, Basbaum AI, Heinricher MM (2006) Central nervous system mechanism of pain modulation. In: The textbook of pain (McMahon SB, Koltzenburg M, eds) pp 125-142. London: Elsevier.

Folbergrová J, Druga R, Haugvicová R, Mares P, Otáhal J (2008) Anticonvulsant and neuroprotective effect of (S)-3,4-dicarboxyphenylglycine against seizures induced in immature rats by homocysteic acid. Neuropharmacology 54:665-675.

Fox RJ, Sorenson CA (1994) Bilateral lesions of the amygdala attenuate analgesia induced by diverse environmental challenges. Brain Res 648:215-221.

Fu Y, Neugebauer V (2008) Differential mechanisms of CRF1 and CRF2 receptor functions in the amygdala in pain-related synaptic facilitation and behavior. J Neurosci 28:3861-3876.

Gauriau C, Bernard JF (2002) Pain pathways and parabrachial circuits in the rat. Exp Physiol 87:251-258.

Gebhart GF (2004) Descending modulation of pain. Neurosci Biobehav Rev 27:729-737. 
Greenwood-Van Meerveld B, Gibson M, Gunter W, Shepard J, Foreman R, Myers D (2001) Stereotaxic delivery of corticosterone to the amygdala modulates colonic sensitivity in rats. Brain Res 893:135-142.

Han JS, Neugebauer V (2005) mGluR1 and mGluR5 antagonists in the amygdala inhibit different components of audible and ultrasonic vocalizations in a model of arthritic pain. Pain 113:211-222.

Han JS, Bird GC, Neugebauer V (2004) Enhanced group III mGluRmediated inhibition of pain-related synaptic plasticity in the amygdala. Neuropharmacology 46:918-926.

Han JS, Li W, Neugebauer V (2005) Critical role of calcitonin gene-related peptide 1 receptors in the amygdala in synaptic plasticity and pain behavior. J Neurosci 25:10717-10728.

Heinricher MM, McGaraughty S (1999) Pain-modulating neurons and behavioural state. In: Handbook of behavioural state control (Lydic R, Baghdoyan HA, eds) pp 487-503. New York: CRC.

Heinricher MM, Tortorici V (1994) Interference with GABA transmission in the rostral ventromedial medulla: disinhibition of off-cells as a central mechanism in nociceptive modulation. Neuroscience 63:533-546.

Helmstetter FJ (1992) The amygdala is essential for the expression of conditional hypoalgesia. Behav Neurosci 106:518-528.

Helmstetter FJ, Bellgowan PS (1993) Lesions of the amygdala block conditional hypoalgesia on the tail flick test. Brain Res 612:253-257.

Hermann DM, Luppi PH, Peyron C, Hinckel P, Jouvet M (1997) Afferent projections to the rat nuclei raphe magnus, raphe pallidus and reticularis gigantocellularis pars alpha demonstrated by iontophoretic application of choleratoxin (subunit b). J Chem Neuroanat 13:1-21.

Ikeda R, Takahashi Y, Inoue K, Kato F (2007) NMDA receptor-independent synaptic plasticity in the central amygdala in the rat model of neuropathic pain. Pain 127:161-172.

Ji G, Neugebauer V (2007) Differential effects of CRF1 and CRF2 receptor antagonists on pain-related sensitization of neurons in the central nucleus of the amygdala. J Neurophysiol 97:3893-3904.

Ji G, Neugebauer V (2009) Hemispheric lateralization of pain processing by amygdala neurons. J Neurophysiol 102:2253-2264.

Ji G, Fu Y, Ruppert KA, Neugebauer V (2007) Pain-related anxiety-like behaviour requires CRF1 receptors in the amygdala. Mol Pain 3:13-17.

Kalia M (2005) Neurobiological basis of depression: an update. Metabolism 54[5 Suppl 1]:24-27.

Kawahara H, Yoshida M, Yokoo H, Nishi M, Tanaka M (1993) Psychological stress increases serotonin release in the rat amygdala and prefrontal cortex assessed by in vivo microdialysis. Neurosci Lett 162:81-84.

Kincaid W, Neubert MJ, Xu M, Kim CJ, Heinricher MM (2006) Role for medullary pain facilitating neurons in secondary thermal hyperalgesia. J Neurophysiol 95:33-41.

Kolber BJ, Montana MC, Carrasquillo Y, Xu J, Heinemann SF, Muglia LJ, Gereau RW 4th (2010) Activation of metabotropic glutamate receptor 5 in the amygdala modulates pain-like behavior. J Neurosci 30:8203-8213.

Lavialle-Defaix C, Gautier H, Defaix A, Lapied B, Grolleau F (2006) Differential regulation of two distinct voltage-dependent sodium currents by group III metabotropic glutamate receptor activation in insect pacemaker neurons. J Neurophysiol 96:2437-2450.

Li W, Neugebauer V (2004) Differential roles of mGluR1 and mGluR5 in brief and prolonged nociceptive processing in central amygdala neurons. J Neurophysiol 91:13-24.

Li W, Neugebauer V (2006) Differential changes of group II and group III mGluR function in central amygdala neurons in a model of arthritic pain. J Neurophysiol 96:1803-1815.

Maione S, Palazzo E, de Novellis V, Stella L, Leyva J, Rossi F (1998) Metabotropic glutamate receptors modulate serotonin release in the rat periaqueductal gray matter. Naunyn Schmiedebergs Arch Pharmacol 358:411-417.

Maione S, Bisogno T, de Novellis V, Palazzo E, Cristino L, Valenti M, Petrosino S, Guglielmotti V, Rossi F, Di Marzo V (2006) Elevation of endocannabinoid levels in the ventrolateral periaqueductal grey through inhibition of fatty acid amide hydrolase affects descending nociceptive pathways via both cannabinoid receptor type 1 and transient receptor potential vanilloid type-1 receptors. J Pharmacol Exp Ther 316:969-982.

Manning BH (1998) A lateralized deficit in morphine antinociception after unilateral inactivation of the central amygdala. J Neurosci 18:9453-9470.

Manning BH, Mayer DJ (1995) The central nucleus of the amygdala contributes to the production of morphine antinociception in the rat tail-flick test. J Neurosci 15:8199-8213.
Marabese I, de Novellis V, Palazzo E, Mariani L, Siniscalco D, Rodella L, Rossi F, Maione S (2005) Differential roles of mGlu8 receptors in the regulation of glutamate and gamma-aminobutyric acid release at periaqueductal grey level. Neuropharmacology 49:157-166.

Marabese I, de Novellis V, Palazzo E, Scafuro MA, Vita D, Rossi F, Maione S (2007a) Effects of (S)-3,4-DCPG, an mGlu8 receptor agonist, on inflammatory and neuropathic pain in mice. Neuropharmacology 52:253-262.

Marabese I, Rossi F, Palazzo E, de Novellis V, Starowicz K, Cristino L, Vita D, Gatta L, Guida F, Di Marzo V, Rossi F, Maione S (2007b) Periaqueductal gray metabotropic glutamate receptor subtype 7 and 8 mediate opposite effects on amino acid release, rostral ventromedial medulla cell activities, and thermal nociception. J Neurophysiol 98:43-53.

McGaraughty S, Heinricher MM (2002) Microinjection of morphine into various amygdaloid nuclei differentially affects nociceptive responsiveness and RVM neuronal activity. Pain 96:153-162.

Meagher MW, Arnau RC, Rhudy JL (2001) Pain and emotion: effects of affective picture modulation. Psychosom Med 63:79-90.

Mena NB, Mathur R, Nayar U (1995) Amygdalar involvement in pain. Indian J Physiol Pharmacol 39:339-346.

Millan MJ (1999) The induction of pain: an integrative review. Prog Neurobiol 57:1-164.

Millecamps M, Centeno MV, Berra HH, Rudick CN, Lavarello S, Tkatch T, Apkarian AV (2007) D-cycloserine reduces neuropathic pain behavior through limbic NMDA-mediated circuitry. Pain 132:108-123.

Mo B, Feng N, Renner K, Forster G (2008) Restraint stress increases serotonin release in the central nucleus of the amygdala via activation of corticotropin-releasing factor receptors. Brain Res Bull 76:493-498.

Mörl F, Gröschel M, Leemhuis J, Meyer DK (2002) Intrinsic GABA neurons inhibit proenkephalin gene expression in slice cultures of rat neostriatum. Eur J Neurosci 15:1115-1124.

Nandigama P, Borszcz GS (2003) Affective analgesia following the administration of morphine into the amygdala of rats. Brain Res 959:343-354.

Neubert MJ, Kincaid W, Heinricher MM (2004) Nociceptive facilitating neurons in the rostral ventromedial medulla. Pain 110:158-165.

Neugebauer V (2007) The amygdala: different pains, different mechanisms. Pain 127:1-2.

Neugebauer V, Li W (2002) Processing of nociceptive mechanical and thermal information in central amygdala neurons with knee-joint input. J Neurophysiol 87:103-112.

Neugebauer V, Li W (2003) Differential sensitization of amygdala neurons to afferent inputs in a model of arthritic pain. J Neurophysiol 89:716-727.

Neugebauer V, Li W, Bird GC, Bhave G, Gereau RW $4^{\text {th }}$ (2003) Synaptic plasticity in the amygdala in a model of arthritic pain: differential roles of metabotropic glutamate receptors 1 and 5. J Neurosci 23:52-63.

Neugebauer V, Li W, Bird GC, Han JS (2004) The amygdala and persistent pain. Neuroscientist 10:221-234.

Ossowska K, Konieczny J, Wardas J, Pietraszek M, Kuter K, Wolfarth S, Pilc A (2007) An influence of ligands of metabotropic glutamate receptor subtypes on parkinsonian-like symptoms and the striatopallidal pathway in rats. Amino Acids 32:179-188.

Palazzo E, Marabese I, de Novellis V, Oliva P, Rossi F, Berrino L, Rossi F, Maione S (2001) Metabotropic and NMDA glutamate receptors participate in the cannabinoid-induced antinociception. Neuropharmacology 40:319-326.

Palazzo E, Fu Y, Ji G, Maione S, Neugebauer V (2008) Group III mGluR7 and mGluR8 in the amygdala differentially modulate nocifensive and affective pain behaviors. Neuropharmacology 55:537-545.

Paxinos G, Watson C (1986) The rat brain in stereotaxic coordinates. New York: Academic.

Perrot S, Idänpään-Heikkilä JJ, Guilbaud G, Kayser V (1998) The enhancement of morphine antinociception by a CCKB receptor antagonist in the rat depends on the phase of inflammation and the intensity of carrageenin-induced hyperalgesia. Pain 74:269-274.

Phelps EA, LeDoux JE (2005) Contributions of the amygdala to emotion processing: from animal models to human behavior. Neuron 48:175-187.

Rhudy JL, Meagher MW (2000) Fear and anxiety: divergent effects on human pain thresholds. Pain 84:65-75.

Rizvi TA, Ennis M, Behbehani MM, Shipley MT (1991) Connections between the central nucleus of the amygdala and the midbrain periaqueductal gray: topography and reciprocity. J Comp Neurol 303:121-131.

Schaffhauser H, Knoflach F, Pink JR, Bleuel Z, Cartmell J, Goepfert F, Kemp JA, Richards JG, Adam G, Mutel V (1998) Multiple pathways for regu- 
lation of the $\mathrm{KCl}$-induced [ ${ }^{3} \mathrm{H}$ ]-GABA release by metabotropic glutamate receptors, in primary rat cortical cultures. Brain Res 782:91-104.

Schmid S, Fendt M (2006) Effects of the mGluR8 agonist (S)-3,4-DCPG in the lateral amygdala on acquisition/expression of fear-potentiated startle, synaptic transmission, and plasticity. Neuropharmacology 50:154-164.

Schoepp DD (2001) Unveiling the functions of presynaptic metabotropic glutamate receptors in the central nervous system. J Pharmacol Exp Ther 299:12-20.

Stachowicz K, Kłak K, Pilc A, Chojnacka-Wójcik E (2005) Lack of the antianxiety-like effect of ( $S$ )-3,4-DCPG, an mGlu8 receptor agonist, after central administration in rats. Pharmacol Rep 57:856-860.

Thomas NK, Wright RA, Howson PA, Kingston AE, Schoepp DD, Jane DE (2001) (S)-3,4-DCPG, a potent and selective mGlu8a receptor agonist, activates metabotropic glutamate receptors on primary afferent terminals in the neonatal rat spinal cord. Neuropharmacology 40:311-318.
Van Bockstaele EJ, Chan J, Pickel VM (1996) Input from central nucleus of the amygdala efferents to pericoerulear dendrites, some of which contain tyrosine hydroxylase immunoreactivity. J Neurosci Res 45:289-302.

Wang QP, Nakai Y (1994) The dorsal raphe: an important nucleus in pain modulation. Brain Res Bull 34:575-585.

Watkins LR, Wiertelak EP, McGorry M, Martinez J, Schwartz B, Sisk D, Maier SF (1998) Neurocircuitry of conditioned inhibition of analgesia: effects of amygdala, dorsal raphe, ventral medullary, and spinal cord lesions on antianalgesia in the rat. Behav Neurosci 112:360-378.

Westerink BH (1995) Brain microdialysis and its application for the study of animal behaviour. Behav Brain Res 70:103-124.

Wittmann M, Marino MJ, Bradley SR, Conn PJ (2001) Activation of group III mGluRs inhibits GABAergic and glutamatergic transmission in the substantia nigra pars reticulata. J Neurophysiol 85:1960-1968. 